\title{
Sufentanil infusion before extubation suppresses coughing on emergence without delaying extubation time and reduces postoperative analgesic requirement without increasing nausea and vomiting after desflurane anesthesia
}

\author{
Jea Yeun Lee, Byung Gun Lim, Hye Yoon Park, and Nan Sook Kim \\ Department of Anesthesiology and Pain Medicine, Korea University Guro Hospital, Seoul, Korea
}

Background: Coughing, hypertension, tachycardia, and even laryngospasm can occur due to airway irritation during emergence from anesthesia. We investigated the effect of maintaining a sufentanil infusion during emergence from anesthesia by evaluating the incidence of cough and recovery profiles at extubation.

Methods: In total, eighty-four patients undergoing an elective laparoscopic hysterectomy were randomly divided into two sufentanil groups and a control group. During emergence, sufentanil was administered in the sufentanil groups at a rate of $0.2 \mu \mathrm{g} / \mathrm{kg} / \mathrm{hr}$ (Group S1) or $0.3 \mu \mathrm{g} / \mathrm{kg} / \mathrm{hr}$ (Group S2), and saline was administered to the control group. Cough score, hemodynamic changes, and recovery profiles, such as duration from skin closure to a bispectral index of 80, to eye opening at verbal command, to tracheal extubation and the total duration of study solution infusion, were recorded. The pain score, the total volume of administered patient-controlled analgesia (PCA), and the postoperative nausea and vomiting (PONV) score were evaluated 1, 6, and 24 hours after surgery.

Results: Groups S1 and S2 showed significantly lower cough scores and smaller hemodynamic changes on extubation compared to Group C. Recovery profiles showed no significant differences among the three groups. Pain score, PONV at 1 hour postoperatively, and the total volume of PCA administered at all evaluation times were significantly lower in Groups S1 and S2 than in the control group. However, pain score, and PONV at 6 hours and 24 hours postoperatively showed no significant differences.

Conclusions: A sufentanil infusion $(0.2-0.3 \mu \mathrm{g} / \mathrm{kg} / \mathrm{hr})$ during emergence from desflurane anesthesia may suppress coughing on extubation in patients with body mass indexes (BMI) of 21-26 without delaying extubation time. It may also reduce the postoperative analgesic requirement without increasing PONV. (Korean J Anesthesiol 2012; 62: 512-517)

Key Words: Anesthesia recovery period, Cough, Sufentanil.

\footnotetext{
Received: August 11, 2011. Revised: 1st, October 3, 2011; 2nd, November 4, 2011. Accepted: November 22, 2011.

Corresponding author: Nan Sook Kim, M.D., Ph.D., Department of Anesthesiology and Pain Medicine, Korea University Guro Hospital, Guro 2-dong, Guro-gu, Seoul 152-703, Korea. Tel: 82-2-2626-1437, Fax: 82-2-851-9897, E-mail: nskim@korea.ac.kr

(c) This is an open-access article distributed under the terms of the Creative Commons Attribution Non-Commercial License (http:// creativecommons.org/licenses/by-nc/3.0/), which permits unrestricted non-commercial use, distribution, and reproduction in any medium, provided the original work is properly cited.
} 


\section{Introduction}

Emergence from general anesthesia is a critical period when endotracheal extubation is performed. During extubation, coughing, hypertension, tachycardia, and even laryngospasm can occur due to airway irritation by the endotracheal tube (ETT). These hyperdynamic reactions can lead to adverse outcomes, such as myocardial ischemia and arrhythmia in susceptible individuals [1]. Various methods using lidocaine, remifentanil, alfentanil, and fentanyl have been devised to promote a quiet and uneventful emergence by suppressing the cough reflex [2-5], and it has been shown that analgesia provided by opioids helps patients tolerate the ETT during extubation without coughing.

Many studies have demonstrated the effectiveness of using a short-acting opioid and the use of remifentanil infusion to provide quiet and uneventful emergence $[3,6,7]$. As sufentanil has a longer duration of action than remifentanil, it is possible that sufentanil infusion could reduce postoperative pain [8]. We postulated that sufentanil infusion may have the additional benefit of avoiding the hyperalgesia associated with remifentanil infusion [9-11].

The purpose of this study was to evaluate the effects of maintaining a sufentanil infusion during emergence from desflurane anesthesia by documenting the incidence of coughing, hemodynamic changes, recovery profile, pain score, the total amount of administered analgesics, and the incidence of postoperative nausea and vomiting (PONV).

\section{Materials and Methods}

We obtained the approval of the Institutional Review Board and written informed consent from the participants. In total, eighty-four patients (American Society of Anesthesiologists physical status classification I-II; age, 35-60 years) who underwent elective laparoscopic hysterectomy by the same surgeon were enrolled in this randomized, double-blind, placebo-controlled study. Patients with a reactive airway

Table 1. Patient Demographics and Clinical Data

\begin{tabular}{lccc}
\hline & \multicolumn{3}{c}{ Group } \\
\cline { 2 - 4 } & $\mathrm{S} 1(\mathrm{n}=28)$ & $\mathrm{S} 2(\mathrm{n}=28)$ & $\mathrm{C}(\mathrm{n}=25)$ \\
\hline Age $(\mathrm{yr})$ & $44.6 \pm 5.9$ & $45.4 \pm 4.5$ & $45.2 \pm 5.0$ \\
Weight $(\mathrm{kg})$ & $58.0 \pm 7.0$ & $58.3 \pm 5.9$ & $58.5 \pm 8.5$ \\
BMI $\left(\mathrm{kg} / \mathrm{m}^{2}\right)$ & $23.6 \pm 2.2$ & $24.0 \pm 2.3$ & $23.4 \pm 3.1$ \\
Ane. Time (min) & $130.0 \pm 36.9$ & $140.5 \pm 30.4$ & $132.4 \pm 30.9$ \\
\hline
\end{tabular}

Values are expressed as mean \pm SD. No significant differences were observedamong the three groups. Group S1: sufentanil infusion 0.2 $\mu \mathrm{g} / \mathrm{kg} / \mathrm{hr}$, Group S2: sufentanil infusion $0.3 \mu \mathrm{g} / \mathrm{kg} / \mathrm{hr}$, Group C: saline infusion, BMI: Body mass index, Ane. Time: total anesthesia time. disease (asthma, chronic obstructive lung disease, or a history of chronic coughing), a history of hypertension, a history of cerebrovascular attack, risk factors for perioperative aspiration, opioid hypersensitivity, and a body mass index (BMI) $\geq 30$ were excluded from this study. Three of the eighty-four patients were excluded based on these criteria. The demographic data of the 81 patients are given in Table 1 . No statistically significant differences were found among the groups for age, weight, BMI, or anesthesia time.

All participants were premedicated with $0.2 \mathrm{mg}$ glycopyrrolate i.m. and $2 \mathrm{mg}$ midazolam i.m. 30 minutes before anesthesia induction. After placement of routine monitors (electrocardiogram, non-invasive blood pressure, pulse oximetry; S/5 Avance ${ }^{\circledR}$ Carestation Anesthesia monitor, Datexohmeda, Finland) and bispectral index (BIS ${ }^{\mathrm{TM}}$, Covidien, California, USA), anesthesia was induced with $5 \mathrm{mg} / \mathrm{kg}$ thiopental sodium i.v. After loss of consciousness, $0.9 \mathrm{mg} / \mathrm{kg}$ rocuronium i.v. was given, and mask ventilation with $100 \%$ oxygen $8 \mathrm{~L} / \mathrm{min}$ and 6 vol\% desflurane was maintained for 3 minutes. Intubation was performed with an ETT (ID 7.0 Sheridan ${ }^{\circledR}$ Cuffed $^{\mathrm{TM}}$, Teleflex Medical, Durham, USA). The cuff was inflated with air, and the cuff-pressure was measured every 10 minutes during the operation using a handheld aneroid manometer to maintain the pressure at $18-25 \mathrm{cmH}_{2} \mathrm{O}$. Anesthesia was maintained with $4-6$ vol\% desflurane, $1.5 \mathrm{~L} / \mathrm{min}$ oxygen, and $1.5 \mathrm{~L} / \mathrm{min}$ nitrous oxide. Desflurane was titrated to maintain BIS values of 40-50. Tidal volume and respiratory rate were titrated to maintain the end-expired carbon dioxide at $30-$ $35 \mathrm{mmHg}$.

Patients were randomly divided into three groups using the closed envelope method. The sufentanil groups (Group S1 and Group S2) received sufentanil infusion (Sufental ${ }^{\circledR}$, BCWP, Korea), and the control group (Group C) received saline infusion. Group S1 received $0.2 \mu \mathrm{g} / \mathrm{kg} / \mathrm{hr}$ sufentanil infusion, and Group S2 received $0.3 \mu \mathrm{g} / \mathrm{kg} / \mathrm{hr}$ using infusion pumps. An unblinded nurse prepared the infusion solution by diluting $50 \mu \mathrm{g}$ sufentanil in $50 \mathrm{ml}$ saline and setting the infusion pump according to group allocation. The nurse did not participate in subsequent patient care. Palonosetron (0.075 mg i.v.; Aloxi ${ }^{\circledR}$, Helsinn Healthcare, Switzerland) was given after the first incision. After the surgical specimen was procured, the infusion of study solution was started and continued until extubation.

All anesthetics were discontinued after skin closure, and the patients were ventilated with $8 \mathrm{~L} / \mathrm{min}$ oxygen. The endtidal desflurane concentration (Et-Des, vol\%) was recorded just before anesthetics were discontinued, and then tracheal suction was performed during the deep anesthesia. Manual bagging was started after BIS reached 80. ETT decuffing was performed, and verbal commands were given every 30 seconds. After response to verbal commands, the residual neuromuscular 
blockade was reversed with $0.3 \mathrm{mg} / \mathrm{kg}$ pyridostigmine i.v. and $8 \mu \mathrm{g} / \mathrm{kg}$ glycopyrrolate i.v., and the patients were subsequently extubated.

We recorded the heart rate (HR) and mean arterial pressure (MAP) at 5 minute intervals during anesthesia. Baseline HR and MAP were defined as the mean of the two consecutive initial measurements.

The duration from skin closure to a BIS of 80 (T1), to eye opening at verbal command (T2), to tracheal extubation (T3), as well as the duration of study drug infusion (T4) were documented as the recovery profiles. During tracheal extubation, the cough score was documented by an anesthesiologist who was blinded to the group assignments. The cough score was assessed on a four-point scale (0: no cough, 1: single cough, 2: more than one episode of unsustained cough, 3: severe sustained bouts of cough) [12]. Oral suction was performed after endotracheal extubation, and coughing during oral suction was not considered.

Patient-controlled analgesia (PCA) was prepared based on the patient's body weight $(0.2 \mu \mathrm{g} / \mathrm{kg} / \mathrm{ml}$ fentanyl, $1.3 \mu \mathrm{g} / \mathrm{kg} / \mathrm{ml}$ hydromorphone and $50 \mu \mathrm{g} / \mathrm{kg} / \mathrm{ml}$ ketorolac) using a portable infusion pump (Ambix Anaplus, E-Wha Fresenius Kabi, Korea) and connected upon arrival to the post-anesthesia care unit (PACU). Total volume, basal infusion rate, lockout time, and the bolus dose of the PCA pump were $50 \mathrm{ml}, 0.5 \mathrm{ml} / \mathrm{hr}, 15$ minutes, and $0.5 \mathrm{ml}$, respectively. Five $\mathrm{ml}$ of PCA was put aside to use for loading doses.

The pain score was assessed on an 11-point scale (0: no pain and 10: worst possible pain). When the pain score was larger than 4, a PCA loading dose of $1 \mathrm{ml}$ was given. The pain score was reassessed every 10 minutes, and a PCA loading dose was given up to five times. The largest number was defined as the

Table 2. Hemodynamic Changes before and after the Infusion of Study Drug

\begin{tabular}{lclc}
\hline & \multicolumn{3}{c}{ Group } \\
\cline { 2 - 4 } & $\mathrm{S} 1(\mathrm{n}=28)$ & $\mathrm{S} 2(\mathrm{n}=28)$ & $\mathrm{C}(\mathrm{n}=25)$ \\
\hline MAP (mmHg) & & & \\
Pre-infusion & $95.7 \pm 10.7$ & $91.9 \pm 8.8$ & $97.8 \pm 11.9$ \\
Post-infusion & $102.7 \pm 11.2^{*, \dagger}$ & $98.5 \pm 22.3^{*, \dagger}$ & $116.1 \pm 11.6^{\dagger}$ \\
MAP_ch & $7.0 \pm 6.5^{*}$ & $10.1 \pm 9.0^{*}$ & $18.3 \pm 11.5$ \\
HR (beats/min) & & & \\
Pre-infusion & $77.7 \pm 12.2$ & $73.5 \pm 12.1$ & $79.8 \pm 9.8$ \\
Post-infusion & $86.7 \pm 11.5^{*, \dagger}$ & $86.7 \pm 16.3^{*, \dagger}$ & $100.6 \pm 10.2^{\dagger}$ \\
HR_ch & $9.0 \pm 9.9^{*}$ & $13.2 \pm 12.0^{*}$ & $20.8 \pm 10.2$ \\
\hline
\end{tabular}

Values are expressed as mean \pm SD. Group S1: sufentanil infusion 0.2 $\mu \mathrm{g} / \mathrm{kg} / \mathrm{hr}$, Group S2: sufentanil infusion $0.3 \mu \mathrm{g} / \mathrm{kg} / \mathrm{hr}$, Group C: saline infusion, MAP_ch: mean arterial pressure changes before and after the infusion of the study drug, HR_ch: heart rate changes before and after the infusion of the study drug. $* \mathrm{P}<0.05$ compared with group $\mathrm{C}$. ${ }^{\dagger} \mathrm{P}<0.05$ compared with pre-infusion values. pain score at postoperative 1 hour.

The PONV score was assessed on a four-point scale (0: no nausea or vomiting, 1: mild nausea and vomiting without any treatment required, 2: moderate nausea and vomiting that resolved with rescue antiemetics, 3: severe nausea and vomiting that did not respond to rescue antiemetics) [3]. Metoclopramide (10 mg i.v.; Macperan ${ }^{\circledR}$, Dong Wha, Korea) was given as the rescue antiemetic if the patient complained of PONV and required medication, and the PONV score was reassessed 10 minutes later. Respiratory depression was considered to be present when $\mathrm{SpO}_{2}<95 \%$ [13] and was checked at postperative 1 hour.

The pain score, the total volume of administered PCA, and the PONV score were assessed at postoperative 1 hour, 6 hours, and 24 hours.

SPSS (version 12.0, SPSS Inc., Chicago, USA) was used for statistical analysis. All results are expressed as mean \pm standard deviation. Categorical data were analyzed using Fisher's exact test or chi-square test as appropriate. For others, after a normality test was performed by the Shapiro-Wilk test, variables that showed a normal distribution, such as age, body weight, BMI, Et-Des, total amount of analgesics given, and HR, were analyzed by ANOVA and Scheffe test. Other data were analyzed with Kruskal-Wallis and Mann-Whitney U-tests. A P value $<0.05$ was considered statistically significant.

\section{Results}

HR and MAP changes (baseline vs. extubation) were smaller in both Group S1 and Group S2 than in Group C $(\mathrm{P}=0.02$, Table 2).

The recovery profiles, such as end-expired desflurane concentration, $\mathrm{T} 1, \mathrm{~T} 2, \mathrm{~T} 3$, and $\mathrm{T} 4$, were not significantly different among the groups (Table 3).

Group S1 and Group S2 showed significantly lower cough

Table 3. Recovery Profiles

\begin{tabular}{lccc}
\hline & \multicolumn{3}{c}{ Group } \\
\cline { 2 - 4 } & $\mathrm{S} 1(\mathrm{n}=28)$ & $\mathrm{S} 2(\mathrm{n}=28)$ & $\mathrm{C}(\mathrm{n}=25)$ \\
\hline Et Des (vol\%) & $5.3 \pm 0.7$ & $5.2 \pm 0.8$ & $5.4 \pm 0.5$ \\
T1 (min) & $9.78 \pm 5.07$ & $7.46 \pm 3.36$ & $8.36 \pm 3.83$ \\
T2 (min) & $11.43 \pm 4.56$ & $9.79 \pm 3.23$ & $10.50 \pm 3.11$ \\
T3 (min) & $13.75 \pm 6.29$ & $10.87 \pm 3.41$ & $12.42 \pm 3.57$ \\
T4 (min) & $22.96 \pm 9.23$ & $25.93 \pm 9.40$ & $21.55 \pm 7.66$ \\
\hline
\end{tabular}

Values are expressed as mean \pm SD. No significant differences were observed among the three groups. Group S1: sufentanil infusion $0.2 \mu \mathrm{g} / \mathrm{kg} / \mathrm{hr}$, Group S2: sufentanil infusion $0.3 \mu \mathrm{g} / \mathrm{kg} / \mathrm{hr}$, Group C: saline infusion, Et Des; End-tidal desflurane percent just before all anesthetics were discontinued, T1: Duration from skin closure to a BIS of 80, T2: Duration from skin closure to eye opening at verbal command, T3: Duration from skin closure to tracheal extubation, T4; Duration of study drug infusion. 
scores than Group C $(\mathrm{P}<0.05$, Fig. 1).

At postoperative 1 hour, the pain score, the total volume of administered PCA, and the PONV score, were significantly lower in Group S1 and Group S2 than in Group C $(\mathrm{P}<0.05$, Table 4). No respiratory depression was observed in any of the groups.

At postoperative 6 and 24 hours, the pain scores were not significantly different among the groups. The total volume of administered PCA was significantly less in both Groups S1 and S2 than in Group C $(\mathrm{P}<0.05$, Table 4$)$. PONV scores were not different among the groups (Table 4 ).

More patients in Group S2 $(n=9)$ than in Group S1 $(n=6)$ needed rescue antiemetics, but no significant difference was observed.

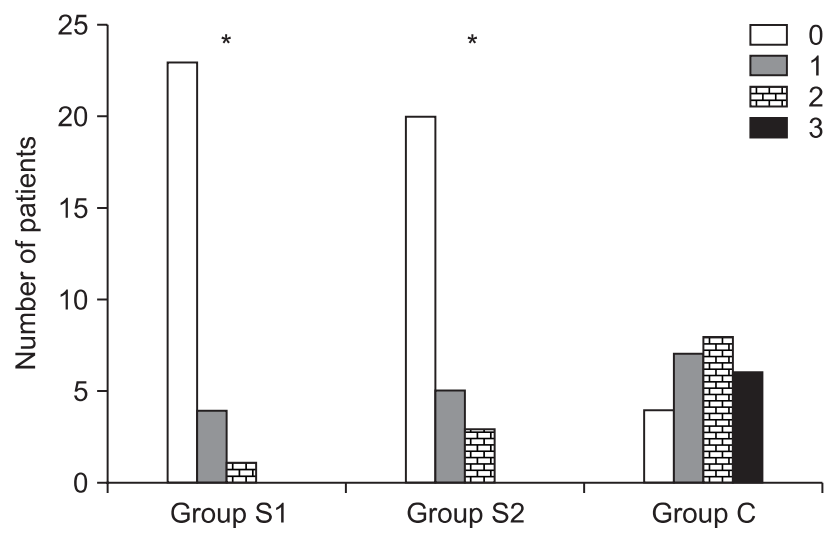

Fig. 1. Comparison of cough scores among the groups. Cough scores were assessed on a 4-point scale ( 0 : no cough, 1: single cough, 2: more than one episode of unsustained cough, and 3: severe sustained bouts of cough). Group S1: sufentanil infusion $0.2 \mu \mathrm{g} / \mathrm{kg} / \mathrm{hr}$, Group S2: sufentanil infusion $0.3 \mu \mathrm{g} / \mathrm{kg} / \mathrm{hr}$, Group C: saline infusion. $* \mathrm{P}<0.05$ compared with group $\mathrm{C}$.

\section{Discussion}

The significantly lower cough scores in the sufentanil infusion groups compared to the control group suggests that sufentanil infusion during emergence from desflurane anesthesia helps suppress coughing during extubation.

Various drugs have been used to suppress the cough reflex during emergence [2-5]. The present study shows that analgesia via $0.2-0.3 \mu \mathrm{g} / \mathrm{kg} / \mathrm{hr}$ sufentanil infusion helps patients tolerate ETT without coughing at extubation time.

Many studies demonstrated that remifentanil helps suppress the cough reflex $[3,6,7]$. Lee et al. [2] showed that remifentanil target controlled-infusion (TCI) at an effect site concentration of $2.0 \mathrm{ng} / \mathrm{ml}$ is more effective for reducing responsiveness to the ETT during emergence from general anesthesia than 1.5 $\mathrm{mg} / \mathrm{ml}$ lidocaine i.v., and Lee et al. [7] found that maintaining remifentanil TCI at $2.14 \mathrm{ng} / \mathrm{ml}$ is a reliable method for abolishing cough and providing smooth emergence from anesthesia.

The rapid onset and short duration of remifentanil, which enables easy titration, also results in termination of analgesic effects within minutes of discontinuing the infusion. Furthermore, hyperalgesia associated with longterm remifentanil infusion has been reported [9-11]. However, the infusion of sufentanil in our study showed reduced postoperative analgesic requirements without resulting in hyperalgesia. This reduction might have occurred due to the facts that the infusion of sufentanil in our study continued for less than 30 minutes, and the context-sensitive half life of sufentanil is longer than that of remifentanil [9].

Concerns have been reported regarding sufentanil infusions, as it has a relatively long duration of action. A report has also shown that sufentanil TCI results in slower awakening in morbidly obese patients [8], so we questioned if a different result would be obtained in patients with BMIs within the normal range and the infusion time was less than 30 minutes.

Table 4. Pain Scores, Total Volumes of Administered PCA, and PONV Scores

\begin{tabular}{|c|c|c|c|c|}
\hline \multirow{2}{*}{\multicolumn{2}{|c|}{ Assessed time }} & \multicolumn{3}{|c|}{ Group } \\
\hline & & \multirow{2}{*}{$\begin{array}{r}\mathrm{S} 1(\mathrm{n}=28) \\
4.0 \pm 2.6^{*}\end{array}$} & \multirow{2}{*}{$\begin{array}{r}\mathrm{S} 2(\mathrm{n}=28) \\
3.5 \pm 1.5^{*}\end{array}$} & \multirow{2}{*}{$\begin{array}{c}C(\mathrm{n}=25) \\
5.0 \pm 2.1\end{array}$} \\
\hline Postoperative & Pain score & & & \\
\hline $1 \mathrm{hr}$ & V. PCA (ml) & $2.18 \pm 1.38^{*}$ & $1.98 \pm 1.60^{*}$ & $3.08 \pm 1.79$ \\
\hline & PONV score & $0.18 \pm 0.55^{*}$ & $0.14 \pm 0.45^{*}$ & $0.48 \pm 0.51$ \\
\hline Postoperative & Pain score & $3.6 \pm 2.0$ & $2.9 \pm 1.0$ & $3.8 \pm 1.9$ \\
\hline \multirow[t]{2}{*}{$6 \mathrm{hr}$} & V. PCA (ml) & $6.73 \pm 1.98^{*}$ & $6.09 \pm 1.92^{*}$ & $8.78 \pm 3.63$ \\
\hline & PONV score & $0.43 \pm 0.74$ & $0.39 \pm 0.79$ & $0.72 \pm 0.84$ \\
\hline Postoperative & Pain score & $2.8 \pm 1.5$ & $2.9 \pm 1.3$ & $3.2 \pm 1.4$ \\
\hline \multirow[t]{2}{*}{$24 \mathrm{hr}$} & V. PCA (ml) & $18.41 \pm 3.55^{*}$ & $16.48 \pm 4.07^{*}$ & $21.52 \pm 4.98$ \\
\hline & PONV score & $0.14 \pm 0.36$ & $0.36 \pm 0.68$ & $0.24 \pm 0.44$ \\
\hline
\end{tabular}

Values are expressed as mean \pm SD. Group S1: sufentanil infusion $0.2 \mu \mathrm{g} / \mathrm{kg} / \mathrm{hr}$, Group S2: sufentanil infusion $0.3 \mu \mathrm{g} / \mathrm{kg} / \mathrm{hr}$, Group C: saline infusion, V. PCA: Total volume of administered patient-controlled analgesia, PONV: postoperative nausea and vomiting. $* \mathrm{P}<0.05$ compared with group C. 
No statistically significant differences were found in recovery profiles among the groups in our study, indicating that sufentanil infusion does not delay emergence in patients with a BMI of 21-26 when used for less than 30 minutes.

The sufentanil infusion groups showed fewer changes in HR and MAP, indicating that sufentanil infusion attenuates hemodynamic responses associated with endotracheal extubation, similar to other opioids [3-5].

The context-sensitive half life of sufentanil is approximately 15-20 minutes when the infusion duration is 1 hour [14], and as all the participants in this study received sufentanil for less than 1 hour, the analgesia provided by sufentanil would still be effective at postoperative 1 hour but not at postoperative 6 or 24 hours. This explains the significantly lower pain scores and smaller total volume of administered PCA in the sufentanil infusion groups than in the control group at postoperative 1 hour, whereas the pain score did not differ significantly among the groups at postoperative 6 and 24 hours. However, this does not explain the significantly less total volume of PCA at postoperative 6 and 24 hours, or the less volume of PCA administered from 1 to 6 hours and from 6 to 24 hours in the sufentanil groups compared to the control group. One explanation is that sufentanil infusion increased pain thresholds, similar to the findings of Bailey et al. [15], which showed that a bolus injection of sufentanil increases one's pain threshold.

Several possible explanations might be advanced for the significantly lower PONY scores $r$ the significantly lower PONV scores in the sufentanil groups than in the control group at postoperative 1 hour. The administration of the prophylactic antiemetic might have served the role for this phenomenon, as the participants in this study were at high risk for PONV $[16,17]$. Furthermore, a sufentanil infusion of $0.2-0.3 \mu \mathrm{g} / \mathrm{kg} / \mathrm{hr}$ may be an insufficient dose to induce PONV. The lower cough score in the sufentanil groups could have also played a role, because if the patient coughs less, the pharynx, which transmits a signal to the emetic center, would be less stimulated, resulting in less signal transmission. Opioids increase PONV, so rather than concluding from the results of this study that sufentanil infusion may decrease PONV, it would be more appropriate to conclude that a $0.2-0.3 \mu \mathrm{g} / \mathrm{kg} / \mathrm{hr}$ sufentanil infusion does not significantly increase PONV when prophylactic antiemetics are used.

Hilberman and Hyer [18] calculated that an infusion rate of $0.15-0.3 \mu \mathrm{g} / \mathrm{kg} / \mathrm{hr}$ sufentanil is effective for balanced anesthesia without causing excess respiratory depression. These reports could explain why no respiratory depression was observed in our participants. Moreover, Kroll and List [19] reported that sufentanil infusion of $0.25-0.35 \mu \mathrm{g} / \mathrm{kg} /$ $\mathrm{hr}$ provided adequate analgesia in critically ill patients being weaned from mechanical ventilation. Thus, the infusion rates of 0.2 and $0.3 \mu \mathrm{g} / \mathrm{kg} / \mathrm{hr}$ in our study was adequate for providing analgesia without respiratory depression.

No significant differences among variables were observed between the two sufentanil groups. Although no significant increases in side effects were seen, no significant benefits were associated with a larger infusion dose. Therefore, $0.2 \mu \mathrm{g} /$ $\mathrm{kg} / \mathrm{hr}$ sufentanil may be a more appropriate infusion dose for suppressing coughing on extubation.

A possible criticism of this study may be that the sufentanil infusion was administered at a constant rate instead of TCI. Thus, the plasma concentration of sufentanil that suppresses coughing without delaying emergence from anesthesia cannot be deduced from our results. Nevertheless, the implication of this study remains unchanged.

In summary, sufentanil infusion at a rate of $0.2-0.3 \mu \mathrm{g} / \mathrm{kg} /$ $\mathrm{hr}$ before extubation suppressed coughing on emergence from desflurane anesthesia without delaying extubation times in patients with a BMI of 21-26 and reduced postoperative pain and analgesic requirements.

\section{References}

1. Aouad MT, Al-Alami AA, Nasr VG, Souki FG, Zbeidy RA, SiddikSayyid SM. The effect of low-dose remifentanil on responses to the endotracheal tube during emergence from general anesthesia. Anesth Analg 2009; 108: 1157-60.

2. Lee JH, Koo BN, Jeong JJ, Kim HS, Lee JR. Differential effects of lidocaine and remifentanil on response to the tracheal tube during emergence from general anaesthesia. Br J Anaesth 2011; 106: 410-5.

3. Nho JS, Lee SY, Kang JM, Kim MC, Choi YK, Shin OY, et al. Effects of maintaining a remifentanil infusion on the recovery profiles during emergence from anaesthesia and tracheal extubation. Br J Anaesth 2009; 103: 817-21.

4. Mendel P, Fredman B, White PF. Alfentanil suppresses coughing and agitation during emergence from isoflurane anesthesia. J Clin Anesth 1995; 7: 114-8.

5. Inagaki Y, Shindo H, Mashimo T, Yoshiya I. The effects of epidural fentanyl on hemodynamic responses during emergence from isoflurane anesthesia and tracheal extubation: a comparison with intravenous fentanyl. Anesth Analg 1997; 85: 328-35.

6. Leone M, Rousseau S, Avidan M, Delmas A, Viviand X, Guyot L, et al. Target concentrations of remifentanil with propofol to blunt coughing during intubation, cuff inflation, and tracheal suctioning. Br J Anaesth 2004; 93: 660-3.

7. Lee B, Lee JR, Na S. Targeting smooth emergence: the effect site concentration of remifentanil for preventing cough during emergence during propofol-remifentanil anaesthesia for thyroid surgery. Br J Anaesth 2009; 102: 775-8.

8. Bidgoli J, Delesalle S, De Hert SG, Reiles E, Van der Linden PJ. A randomised trial comparing sufentanil versus remifentanil for laparoscopic gastroplasty in the morbidly obese patient. Eur J Anaesthesiol 2011; 28: 120-4.

9. Wilhelm W, Kreuer S. The place for short-acting opioids: special 
emphasis on remifentanil. Crit Care 2008; 12 Suppl 3: S5.

10. Guignard B, Bossard AE, Coste C, Sessler DI, Lebrault C, Alfonsi P, et al. Acute opioid tolerance: intraoperative remifentanil increases postoperative pain and morphine requirement. Anesthesiology 2000; 93: 409-17.

11. Hood DD, Curry R, Eisenach JC. Intravenous remifentanil produces withdrawal hyperalgesia in volunteers with capsaicin-induced hyperalgesia. Anesth Analg 2003; 97: 810-5.

12. Minogue SC, Ralph J, Lampa MJ. Laryngotracheal topicalization with lidocaine before intubation decreases the incidence of coughing on emergence from general anesthesia. Anesth Analg 2004; 99: 1253-7.

13. Perreault L, Vezina D, Roberts K, Baillargeon R. Low-dose sufentanil in major surgery. Can J Anaesth 1990; 37: 629-35.

14. Derrode N, Lebrun F, Levron JC, Chauvin M, Debaene B. Influence of peroperative opioid on postoperative pain after major abdominal surgery: sufentanil TCI versus remifentanil TCI. A randomized, controlled study. Br J Anaesth 2003; 91: 842-9.

15. Bailey PL, Streisand JB, East KA, East TD, Isern S, Hansen TW, et al. Differences in magnitude and duration of opioid-induced respiratory depression and analgesia with fentanyl and sufentanil. Anesth Analg 1990; 70: 8-15.

16. Apfel CC, Laara E, Koivuranta M, Greim CA, Roewer N. A simplified risk score for predicting postoperative nausea and vomiting: conclusions from cross-validations between two centers. Anesthesiology 1999; 91: 693-700.

17. Rusch D, Eberhart LH, Wallenborn J, Kranke P. Nausea and vomiting after surgery under general anesthesia: an evidence-based review concerning risk assessment, prevention, and treatment. Dtsch Arztebl Int 2010; 107: 733-41.

18. Hilberman M, Hyer D. Potency of sufentanil. Anesthesiology 1986; 64: $665-8$

19. Kroll W, List WF. Is sufentanil suitable for long-term sedation of a critically ill patient? Anaesthesist 1992; 41: 271-5. 